\title{
New Development of the Point Performance of a Bridge Using Stiffness-Based Damage Index and Drift Damage
}

salaheddine harzallah ( $\sim$ harzallahozil@yahoo.fr)

University of Sciences and Technology Houari Boumediene: Universite des Sciences et de la Technologie Houari Boumediene https://orcid.org/0000-0003-0145-1631

\section{Research Article}

Keywords: New point performance, bridge, stiffness-based damage index, drifts damage,nonlinear static analysis

Posted Date: February 4th, 2022

DOI: https://doi.org/10.21203/rs.3.rs-1304090/v1

License: (c) (i) This work is licensed under a Creative Commons Attribution 4.0 International License.

Read Full License 


\title{
New development of the point performance of a bridge using stiffness-based damage index and drift damage
}

\author{
S. Harzallah ${ }^{1}$ \\ Built Environmental Research Lab., Dept. of Structures and Materials, Civil Engineering Faculty, University of \\ Sciences and Technology HouariBoumediene, B.P. 32 El Alia Bab Ezzouar, 16111 Algiers, Algeria. \\ harzallahozil@yahoo.fr,
}

\begin{abstract}
In this present research study, development of the performance point of a bridge using stiffness-based damage index and drift damage to assess damage to reinforced concrete moment resisting frames, is proposed. It is shown that inelastic dynamic time-history analysis is performed on bridge subjected to earthquake records meanwhile damage of the bridge is computed by the stiffness-based damage index. Two relations between damage and drift are derived by applying a superposition that takes into account their effects. It is proven that the proposed point performance and damage indices are able to assess the damage index of bridge frames. The proposed approach is then checked by comparing predicted values to the ones considered as exact in the literature.
\end{abstract}

Keywords:New point performance, bridge, stiffness-based damage index, drifts damage,nonlinear static analysis.

\section{Introduction}

During the long-term service life of structures, such as bridges or buildings, several environmental factors and the aging of structural materials, as well as other events such as natural disasters, can lead to different degrees of structural damages. These latest are mainly due to the continuous deterioration, creep, fatigue, corrosion and also unexpected heavy loads caused by natural phenomena, such as earthquakes, typhoons and strong winds, among others. Structural seismic design for reinforced concrete (RC) constructions requires a design that can sustain repairable damage. During an earthquake exposure, bridges can suffer irreparable damage or even a total collapse. The concept of the predictive method has been relied upon to assess potential seismic performance instead of design practice method. It is defined as a 
performance-based seismic design (PBSD) (Mohd. Zameeruddin et al. 2020). PBSD refers to the strategy of processing and the methodology in which the requirements of structural design are represented in order to achieve a set of performance objectives.

The basic principle of seismic computation provides an acceptable degree of security thus reducing the risks related to failures, disasters and also loss of life. In seismic codes and regulations, the study of the response of structures under seismic action is conducted using simplified methods according to the nature of the structure and its destination. Technical analysis of these structures consists essentially in comparing a "demand" parameter to a "capacity" parameter. The shear force at the base of a structure is a parameter traditionally used for the seismic design of structures. Engineer calculates the stress caused by an earthquake at the base of the structure, and compares it to the resistance of the latter. Otherwise, new techniques for checking and dimensioning RC structures consist in choosing the performance objectives and thus developing an appropriate preliminary design. The evaluation of seismic demand and the capacity of the structure make it possible to verify if the design satisfies the purpose.

The nonlinear calculation is a very useful tool to follow the behavior of structures beyond their elastic and plastic phase. This type of assessment has the advantage of taking into consideration the degradation of the rigidity of the elements constituting the structure and consequently, the redistribution of the internal forces in pieces. These new techniques of verification and design of RC structures are to choose objectives performance and develop appropriate preliminary design, evaluate the seismic demand as well as the capacity of the structure to be checked if the design satisfies the main goal.

Performance objectives are a reasonable probability of the acceptable risk incurring various degrees of damage and potential consequences resulting from damages and failures (Mihai Mihaită,2015).PBSD procedures emerged during the first version of ATC40, FEMA273, second version of FEMA356, and next edition of FEMA 440, concept guide documents share similar processes such: i) identifying performance targets and specifying performance levels associated with a particular earthquake hazard; ii) determining seismic demands of the structure and structural capability through comprehensive structural analysis; iii) Estimate the seismic requirements of the system and the capacity of the structure ; iv) Performance 
evaluation at the system level and the components level (Ghobarah, 2000)(FEMA 445). These methods evaluate the performance of the structure while it is being collapsed, but these methods are also unable to produce the associated damage value.

The ability of a structure to withstand an earthquake may be quantified in terms of the predicted level of damage after an earthquake. Damage can be assessed using one of many damage indices, which are functions with values that can be linked to certain structural damage states. The usefulness of a variety of current response-based damage indices in seismic damage evaluation is reviewed and critically appraised. A novel rational damage assessment technique is provided, which offers an assessment of the structure's physical response characteristics and is better suited for non-linear structural analysis (Ranjkesh, 2019).

In order to evaluate an expected damage to structures when subjected to earthquakes of various intensities, a practical procedure based on static pushover analysis is proposed. The research of ductile and non-ductile RC buildings revealed that the suggested damage assessment process provides a straightforward, consistent, and reasonable damage indicator for structures (Mahboubi, S).

The stiffness-based damage index (DIc) is developed in this study. It is simply formulated based on nonlinear responses that are obtained via nonlinear static techniques.It is handy since only one pushover is required to getthe inertia loads. These latest are required to determine the level of damage to the structure in question.On the other hand, DIc is used to estimate the damage of RC frames that represent various constructions. Damage values are usually linked to a damage index which is dependent on drift according to the DIc results. These resultsare in good agreement in comparison withdrift damage values and are a useful tool for practical applications(Hosseini, S.H).

According to Zhou, for the level of damage sustained up to collapse, performance objectives in performance-based design procedures have been described in a variety of ways. In terms of economy and safety, selecting the appropriate drift associated with various levels of damage for the design is critical. It is proven that one of unresolved issues in the development of performance objectives in performance-based design and assessment procedures is the identification of drift levels associated with different states of damage(Zhou et al., 2017). The 
objective of this research is to develop a method for determining the drift of various structural systems that is associated with different definable levels of damage, which can then be used as performance objectives in the design of new structures and the assessment of structures seismic resistance.

The correlation between drift and damage of various structural elements and systems was investigated using analytical and numerical data. Time-history analysis, dynamic and static pushover analyses of various designs of reinforced concrete walls and moment resisting frames were among used analytical procedures. The appropriateness and consistency of data from recently conducted tests as well as available experimental research results in the literature are examined. Static and dynamic testing of walls and frame components were part of the research. The drift associated with various levels of damage to different reinforced concrete elements and structural systems was discovered to vary significantly.

Using a damage index, an attempt was made to establish a procedure to correlate damage of various structural systems to drift while considering diverse ground motion characteristics (Ghobarah et al. 2001).The relationship between damage and drift should be assessed against experimental work as well as observed structural performance during earthquakes for successful design criteria.

The objective of this research work is development of the performance point of a bridge using stiffness-based damage index and drift damage to assess damage to reinforced concrete moment resisting frames, is proposed. Two relations between damage and drift are derived by applying a superposition that takes into account their effects. It is proven that the proposed point performance and damage indices are able to assess the damage index of bridge frames.

\section{Proposed pushover DI advantages}

The proposed damage assessment method has various advantages. Among these benefits, one can find : (a)The damage index is computed using a rational response analysis approach that requires little calibration, (b) The stiffness of the frame is determined after removing inertia and damping force effects and bringing it to a static state, (c) Without needing to anticipate the structure's maximum displacement or deformation near collapse, damage can be determined at any point during loading, (d) In the pushover analysis, two distinct final 
stiffness can be estimated depending on the load direction. The stiffness index can be calculated using the smaller stiffness; (e) A significant benefit of the suggested approach is that it offers information on element and level damage, as well as the sequence of element damage and failure. To integrate the influence of the frame elements, no averaging or weighting process is required to acquire the level and global damage indices for the entire frame, f) To integrate the effect of the frame elements, the damage indices for the entire frame are calculated without the use of an averaging or weighting process, (g) In addition to flexural yielding, the suggested index can model damage caused by additional other mechanisms (Mohd. Zameeruddin,2021). In this instance, all conceivable failure modes should be included in the analysis models. In the case of reinforced concrete structures, the model should account for shear deformation and reinforcing bar bond slip. Most published damage indices, according toWilliams et al., examined only flexural yielding and did not take into account the likelihood of shear failure. In the damage analysis of existing non-ductile structures, these difficulties are crucial.

\section{Damage Index}

According to what the index accounts for, the response-based damage indices can be classified into three groups: (a) maximum deformation; (b) cumulative damage; and (c) maximum deformation and cumulative damage.

\subsection{Damage indices based on maximum deformation}

a)Ratio of ductility (DR). The maximum deformation to yield deformation ratio is known as the ductility ratio. This ratio has been widely employed in seismic analysis to assess the performance of structures that are subjected to inelastic deformation and also to develop inelastic response spectra(Newmark and Rosenblueth, 1971).DR may be unsatisfactory as a damage index, in particularfor the case where shear distortion in connections and beam bottom bar pullout are expected. It has been proven that DR does not account for the effect of the ground motion's frequency and duration content, as experimental tests have shown.Furthermore, experimental research has shown that the duration and frequency of the ground motion has no effect on the ductility ratio.The structural ductility (capacity), which is equal to the ratio of ultimate deformation under monotonic static load to yield deformation, is overcome by the ductility demand (response) (Mohammad S et al. 2015). 
b) Ratio of slopes (SR).The slope ratio is a measurement of damage caused by stiffness degradation under seismic loading.It is determined from the slope of the loading branch of the force-displacement diagram divided by the slope of the unloading branch of the forcedisplacement diagram. It has been determined that SR values of 0 and 2 correlate to structural behavior that is safe and structural behavior that is considerably damaged, respectively. These extreme figures are based on a study of small-scale structural systems (Toussi and Yao, 1982).

c) Ratio of flexural damage (FDR). The ratio of initial stiffness to reduced secant stiffness at maximum displacement, according to Roufaiel and Meyer, can be used as an indicator of damage. The critical values of the DR, SR, and FDR damage indices are calculated using laboratory tests and field observations.As a result, when predicting seismic damage for structures having attributes that differ significantly from those utilized in the calibration technique, they should be used with caution.

d) Maximum permanent drift.Toussi and Yao gave a thorough overview of plastic deformations in a structural system that was directly related to permanent drift.Stephens and Yao, on the other hand, presented a qualitative estimate of damage that took into account the building's irreversible drift.

\subsection{Damage indices based on cumulative damage}

a)Normalized cumulative rotation (NCR).Morerecently, Banon et al.proposed the normalized cumulative rotation. The sum of all inelastic excursions produced by the structure during a seismic event is a simplified indicator of structural degradation. It is quite obvious that the value of this parameter is determined by the earthquake's duration and intensity. Then, the ratio of the sum of the inelastic rotations throughout half cycles to the yield rotation is known as the NCR.Damage indices based solely on cumulative inelastic deformation or dissipated energy have been shown to be insufficient to characterize the complex process of damage propagation and subsequent failure in concrete members, according to a statistical analysis of data on beam-column elements subjected to cyclic loads.Only few studies on this phenomenon have been reported in the literature. 
b) Low cycle fatigue (LCF).Using seismic data, the concept of low-cycle fatigue has been utilized to assess the status of damage in structures subjected to extreme ground motion.Miner.DI was created by Miner and is calculated in a complex fashion that considers the full response history.The maximum inelastic deformation, however, was not taken into account by the index.For more details, the reader is referred to the work by Wang and Feng.

c) Local damage index of Park and Ang.Local damage index has received significant attention in the past three decades. Park and Ang were among the pioneer to be able to calculate the damage index using scaled values of the local element's ductility and dissipated energy during seismic ground shaking.The ductility is scaled by the ratio of the ultimate deformation under a monotonic static load to the yield deformation. It is defined as the ratio of the highest deformation to the yield deformation. In order to determine DI, one has to perform some experimental calibration. For the case of a concrete when it achieves a certain ultimate strain, the ultimate deformation is identified. Despite the fact that the index's value may exceed unity, Chung et aldeveloped DI, where a crucialparameter was introduced such asdamage modifiers that account for the loading history's effect. It is noticed that this indicator takes into consideration various responses of members that react to positive and negative moments. It is obvious that a damage modifier is used to account for the influence of the loading history, which includes the decrease in stiffness and the bending moment sustained up to the calculation cycle. The greatest deformation experienced by the element is not explicitly accounted for in the damage index formulation.

d) Maximum softening.DiPasquale and Cakmakproposed a damage model for a succession of non-overlapping time windows based on the evolution of the natural period of a timevarying linear system that is equivalent to the actual non-linear system. The combined effect of stiffness deterioration and plastic deformation is used to calculate this global damage index. In order to compute the maximum softening, the input ground acceleration as well as the acceleration at another position, such as the top of the structure, is required.The maximum DI does not account for dissipated energy or a decrease in strength, nor does it provide details on the extent of local damage.Besides, the change in the structure's initial fundamental period was employed by DiPasquale and Cakmak as a measure of the vibration's effect on rigidity.The effect of inertia and damping forces, on the other hand, is included in the instantaneous fundamental period. Then, the benefit of evaluating the final softening from the initial natural period and the final period derived from vibration field testing after the 
earthquake, can be significant. In practice, knowing the actual structural reaction is not necessary.

\section{Global Damage}

Several damage indicesdefined in previous sub-sections, including NCR ,DR, LCF, Chung et al,Park and Ang,describe the local damage incurred forparticular structural elements. Local damage indices are used to identify weak or sensitive components that need to be repaired. However, a large list of element damage indices makes it hard to acquire a clear picture of a structural response to a particular movement. A single overall or global damage index is presently used to make important decisions about a damaged structure's residual strength and safety. Global indices are necessary fordamage assessment and structural appraisal after the earthquake, reliability studies, and applications in the performance-based engineering method (PBSD).

\subsection{Stiffness-based damage index}

Stiffness-based damage index of the entire frame is given as follows;

$$
D I_{k}=1-\frac{k_{\text {final }}}{k_{\text {initial }}}
$$

where $K_{\text {inital }}$ is the slope of the base shear-top deflection resulting from pushover analyses of the frame before subjecting it to the earthquake ground motion and $\mathrm{K}_{\text {final }}$ is the initial slope of the same relationship but after subjecting the frame to the earthquake (time history) (after Julian Carrillo).

In order to remove the limitations of the stiffness DI, a cumulative effect has been established using the same formula as identified in Eq. (1), rewritten under the form;

$$
D I_{c}=1-\frac{k_{c}}{k_{0}}
$$

where DIcrepresents the damage at collapse, $K c$ is the instantaneous stiffness at an intended performance level, and $K_{0}$ represents the stiffness at the operational level 


$$
\left[\begin{array}{ccccccc}
d_{1} & 0 & 0 & & \ldots & \ldots & 0 \\
d_{1} & d_{2}-d_{1} & 0 & & \ldots & \ldots & 0 \\
d_{1} & d_{2}-d_{1} & d_{3}-d_{2} & & \ldots & \ldots & \ldots \\
\vdots & \vdots & \vdots & \vdots: \vdots & \vdots: \vdots & & 0 \\
\vdots & \vdots & \vdots & \vdots \vdots \vdots & \vdots: \vdots & & \vdots: \vdots \\
d_{1} & d_{2}-d_{1} & d_{3}-d_{2} & \ldots & \ldots & d_{n}-d_{n-1}
\end{array}\right]\left[\begin{array}{c}
K_{0} \\
K_{1} \\
K_{2} \\
\vdots \\
\vdots \\
K_{n-1}
\end{array}\right]=\left[\begin{array}{c}
V_{1} \\
V_{2} \\
V_{3} \\
\vdots \\
\vdots \\
V_{n}
\end{array}\right](3)
$$

$$
V_{n}=\sum_{i=0}^{n-1}\left(d_{i+1}-d_{i}\right) K_{i}
$$

$$
V_{n+1}=\sum_{i=0}^{n}\left(d_{i+1}-d_{i}\right) K_{i}
$$

$$
\left(1-D I_{c}\right) K_{0}=K_{c}
$$

$$
\left(1-D I_{c}\right) d_{c} K_{0}=d_{c} k_{c}
$$

$$
\left(1-D I_{c}\right) d_{c} K_{0}=V_{c}
$$

We set $c=n+1$ and $n=c-1$

$$
\begin{aligned}
& V_{c}=\sum_{i=0}^{c-1}\left(d_{i+1}-d_{i}\right) K_{i} \\
& V_{c}=K_{n}\left(d_{c}-d_{n}\right)+\sum_{i=0}^{n-1}\left(d_{i+1}-d_{i}\right) K_{i} \\
& D I_{C}=1-\frac{V_{c}}{k_{0} d_{c}} \\
& D I_{C}=1-\frac{K_{n}\left(d_{c}-d_{n}\right)+\sum_{i=0}^{n-1}\left(d_{i+1}-d_{i}\right) K_{i}}{k_{0} d_{c}} \\
& D I_{C, I O}=1-\frac{K_{I O}\left(d_{I O}-d_{n}\right)+\sum_{i=0}^{n-1}\left(d_{i+1}-d_{i}\right) K_{i}}{k_{0} d_{c}} \\
& D I_{C, L S}=1-\frac{K_{L S}\left(d_{L S}-d_{n}\right)+\sum_{i=0}^{n-1}\left(d_{i+1}-d_{i}\right) K_{i}}{k_{0} d_{c}} \\
& D I_{C, C P}=1-\frac{K_{C P}\left(d_{C P}-d_{n}\right)+\sum_{i=0}^{n-1}\left(d_{i+1}-d_{i}\right) K_{i}}{k_{0} d_{c}}
\end{aligned}
$$




\section{Problem formulation}

\subsection{Description of the structure}

The bridge used in research work is a slab bridge with two continuous spans, and a pier of two columns as shown in Figure 1with an overall plan and a view of the bridge. On the other side, Figure 3 shows a transverse section of the pier bridge.

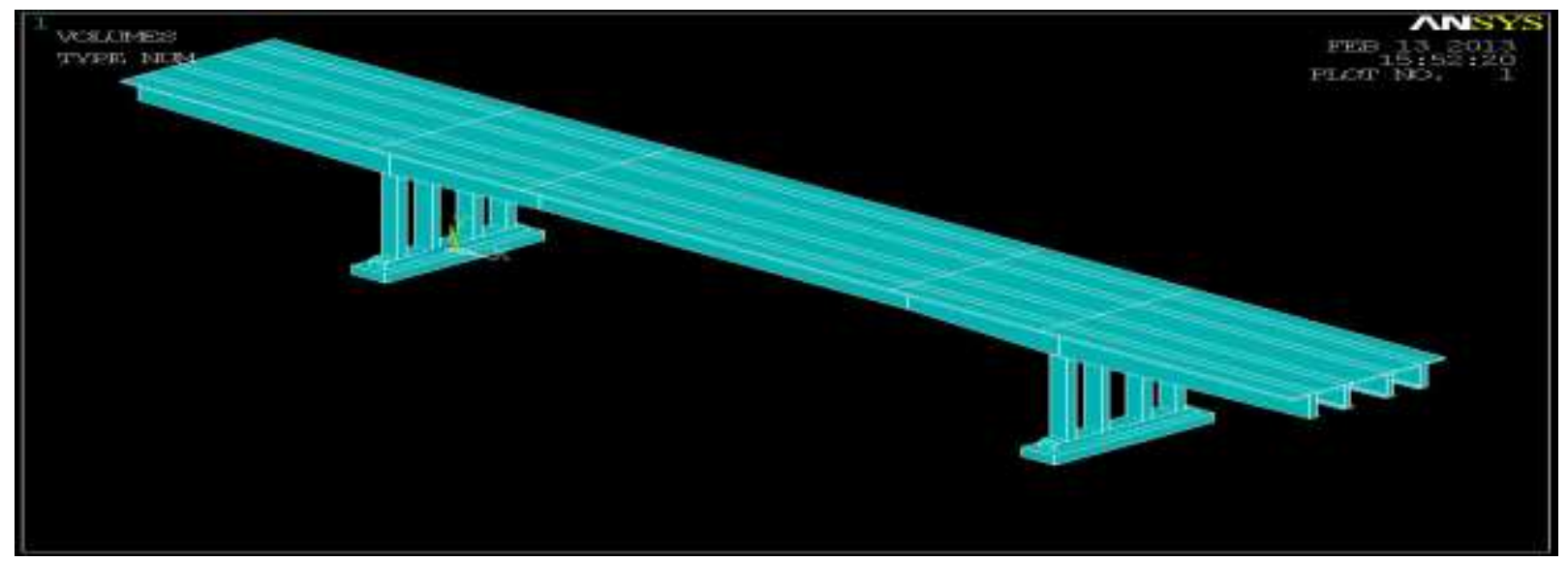

Figure 1.Longitudinal section of the bridge.

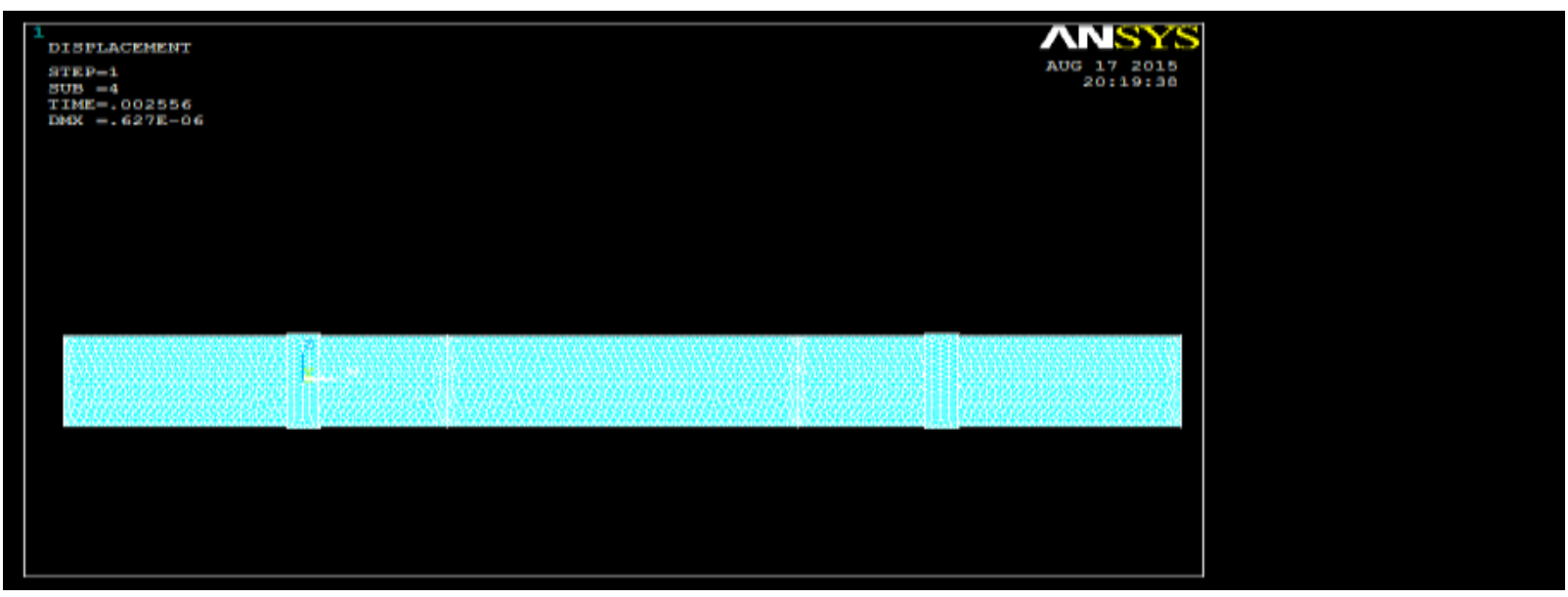

Figure 2.Overall plan and view of the bridge.

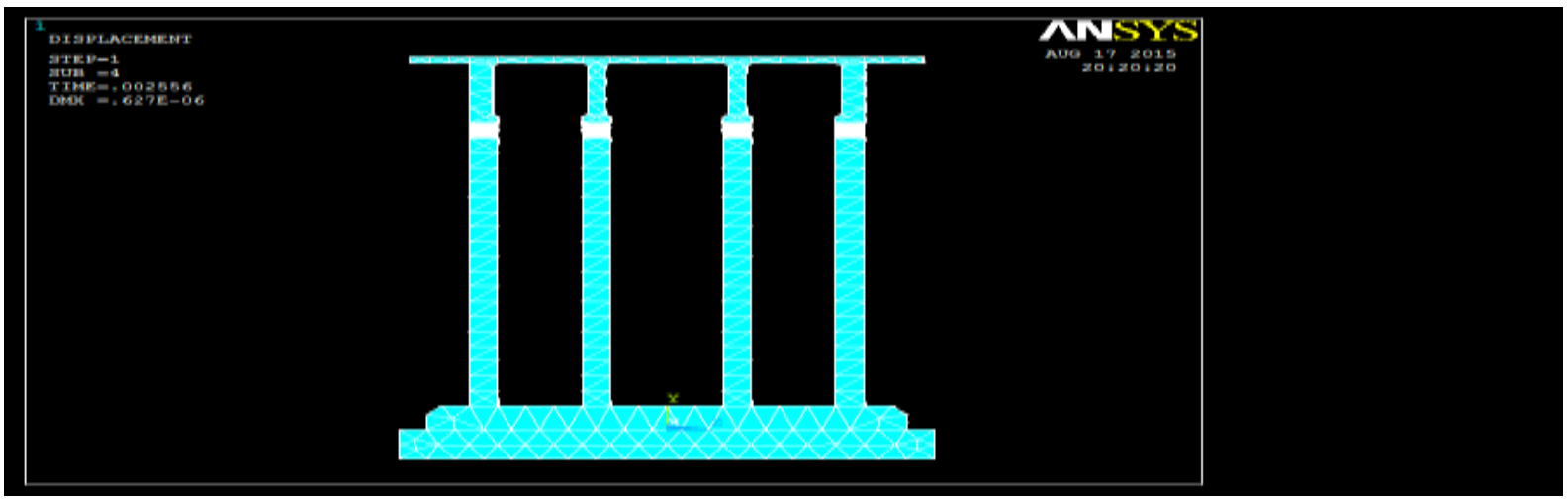

Figure 3.Transverse section of the pier. 
These figures illustrate the calculation of the total weight of the bridge. The total weight is $\mathrm{Mg}$ $=27850.36 \mathrm{kN}$ where $\mathrm{M}$ is the total mass of the bridge and g means gravity.

\subsection{Definition of materials}

The material being formed of any mixture and the discretization in tetrahedral elements being arbitrary, we were led to consider for all the elements the same calculated properties. The reinforced concrete is mainly composed of two materials which are concrete (matrix m) and steel (fibers $\mathrm{f}$ ) to form a mixture of materials. The law of mixtures allows it possible to establish its properties using volume fractions (refer to Leila Soufeiania)

Unidirectional fibers give the maximum properties according to the direction of the fibres corresponding to the case of the simple arrangement. Furthermore, they provide the minimum properties in the transverse direction. On the other hand, the law of mixtures is a good representation of the experiment. This is why an analogy formulation was used by Ferreira for the shell finite elements.

We have introduced the composite reinforced concrete strength for the uniquedesigned bridge construction in the composite mixtures laws with:

$$
S_{r c}=\left(v_{f}+v_{m} \frac{E_{m}}{E_{f}}\right)
$$

Equation (16) is the originality in this research for a specific structural case which includes the effects of steel reinforcement in the concrete structure. Material strength stresses are given in Table 1 where $S_{\mathrm{f}}$ is the steelyield strength, $S_{\mathrm{m}}$ is the concrete yield strength and $S_{\mathrm{rc}}$ is the reinforced concrete (RC) (Doo-YeolYooet al),(Bathias,2009).

Volumes fractions of steel as fibers (f) and volumes fractions of concrete matrix (m) are related as;

$$
\mathrm{v}_{\mathrm{m}}+\mathrm{v}_{\mathrm{f}}=1
$$

where; $v_{m}$ and $v_{f}$ are the concrete and steel volume fractions, respectively.

Let $\mathrm{V}_{\mathrm{f}}$ be the volume of steel, $\mathrm{V}_{\mathrm{m}}$ the volume of concrete and $\mathrm{V}_{\mathrm{rc}}$ the volume of reinforced concrete then we get;

$$
\begin{gathered}
v_{f}=\frac{v_{f}}{v_{r c}} \\
v_{m}=\frac{v_{m}}{v_{r c}}=1-v_{f}
\end{gathered}
$$


The mechanical properties of matrix materials $[\mathrm{D}-1](6 \times 6)$ are expressed in terms of the properties of heterogeneous materials RC from Hooke's general law under the following form;

$$
\left(\begin{array}{c}
\varepsilon_{x x} \\
\varepsilon_{y y} \\
\varepsilon_{z z} \\
\varepsilon_{y z} \\
\varepsilon_{z x} \\
\varepsilon_{x y}
\end{array}\right)=\left(\begin{array}{ccccccc}
\frac{1}{E_{r c}} & -\frac{v_{r c}}{E_{r c}} & -\frac{v_{r c}}{E_{r c}} & 0 & 0 & 0 \\
-\frac{v_{r c}}{E_{r c}} & \frac{1}{E_{r c}} & -\frac{v_{r c}}{E_{r c}} & 0 & 0 & 0 \\
-\frac{v_{r c}}{E_{r c}} & -\frac{v_{r c}}{E_{r c}} \frac{1}{E_{r c}} & 0 & 0 & 0 \\
0 & 0 & 0 & \frac{1}{2 G_{r c}} & 0 & 0 \\
0 & 0 & 0 & 0 & \frac{1}{2 G_{r c}} & 0 \\
0 & 0 & 0 & 0 & 0 & \frac{1}{2 G_{r c}}
\end{array}\right)\left(\begin{array}{c}
\sigma_{x x} \\
\sigma_{y y} \\
\sigma_{z z} \\
\sigma_{y z} \\
\sigma_{z x} \\
\sigma_{x y}
\end{array}\right)
$$

where; $E_{r c}$ and $v_{r c}$ correspond to the Young's modulus and Poisson's ratio, respectively. $G_{r c}$ is the shear modulus.

$$
\left\{\begin{array}{l}
E_{r c}=E_{m} v_{m}+E_{f} v_{f} \\
v_{r c}=V_{m} v_{m}+V_{f} v_{f} \\
\rho_{r c}=\rho_{m} v_{m}+\rho_{f} v_{f} \\
\frac{1}{G_{r c}}=\frac{v_{m}}{G_{m}}+\frac{v_{f}}{G_{f}}
\end{array}\right.
$$

For the example of OuedOumazer bridge, given data considered in this study are listed in the following Table 1.

\begin{tabular}{|c|c|c|c|c|c|c|c|}
\hline \multicolumn{8}{|c|}{ Characteristics of fiber and matrix mixture } \\
\hline $\begin{array}{c}E_{m} \\
{[\mathrm{MPa}]}\end{array}$ & $\begin{array}{c}E_{f} \\
{[\mathrm{MPa}]}\end{array}$ & $\begin{array}{c}G_{m} \\
{[\mathrm{MPa}]}\end{array}$ & $\begin{array}{c}G_{f} \\
{[\mathrm{MPa}]}\end{array}$ & $\begin{array}{c}\rho_{m} \\
{\left[\mathrm{~kg} / \mathrm{m}^{3}\right]}\end{array}$ & $\begin{array}{c}\rho_{f} \\
{\left[\mathrm{~kg} / \mathrm{m}^{3}\right]}\end{array}$ & $v_{m}$ & $v_{f}$ \\
\hline 30798 & 207000 & 12319 & 80233 & 2402.8 & 7850 & 0.25 & 0.29 \\
\hline \multicolumn{4}{|c|}{$\begin{array}{c}\text { Characteristics of reinforced concrete and } \\
\text { steel }\end{array}$} & \multicolumn{4}{|c|}{ Characteristics of the mixture of materials } \\
\hline $\begin{array}{c}V_{r c} \\
{\left[\mathrm{~m}^{3}\right]}\end{array}$ & $\begin{array}{c}V_{f} \\
{\left[\mathrm{~m}^{3}\right]}\end{array}$ & $\begin{array}{l}M_{r c} \\
{[\mathrm{~kg}]}\end{array}$ & $\begin{array}{c}M_{f} \\
{[\mathrm{~kg}]}\end{array}$ & $\begin{array}{c}E_{r c} \\
{[\mathrm{MPa}]}\end{array}$ & $v_{r c}$ & $\begin{array}{c}\rho_{r c} \\
{\left[\mathrm{~kg} / \mathrm{m}^{3}\right]}\end{array}$ & $\begin{array}{c}G_{r c} \\
{[\mathrm{MPa}]}\end{array}$ \\
\hline 410.76 & 7.849 & $10.28 * 10^{3}$ & 61614 & 34165 & 0.2508 & 2506.87 & 12522 \\
\hline
\end{tabular}

Table 1.Characteristics of fiber and matrix mixture.

\subsection{Elements cross-sections}

Table 2 gives the dimensions of the sections of Bridge Piers and is represented graphically in Figure 3. 
Table 2.Transverse sections of elements.

\begin{tabular}{|c|c|c|c|c|c|}
\hline Elements & $\mathrm{b}(\mathrm{m})$ & $\mathrm{h}(\mathrm{m})$ & $\mathrm{d}(\mathrm{m})$ & $\mathrm{A}\left(\mathrm{m}^{2}\right)$ & $\mathrm{I}\left(\mathrm{m}^{4}\right)$ \\
\hline Crosshead & 1.2 & 2.1 & - & 2.52 & 0,3038 \\
\hline Columns & 1.2 & 1.4 & - & 1.68 & 0.2744 \\
\hline
\end{tabular}

where; band $\mathrm{h}$ are the width and the height of the crosshead, respectively. $\mathrm{d}$ is the diameter of columns, $\mathrm{I}$ is the moment of inertia, $\mathrm{A}$ is the area of the element and $\mathrm{W}=576.43 \mathrm{kN} / \mathrm{ml}$.

\section{Nonlinear dynamic analysis}

Let us consider the proposed Bridge Piers, subjected to the earthquake of Boumerdes (Algeria) which is classified by the RPA 99/version2003 (CGS, 2003) as zone III a very high seismicity zone. The response spectrums on the displacement (a), in pseudo speed (b) and in pseudo acceleration are taken from (C.G.S,2003). An earthquake accelerogram May 21, 2003 Boumerdes is shown in Figure 4and the response spectrum conversion in acceleration to a spectrum of demand is represented in Figure 5.

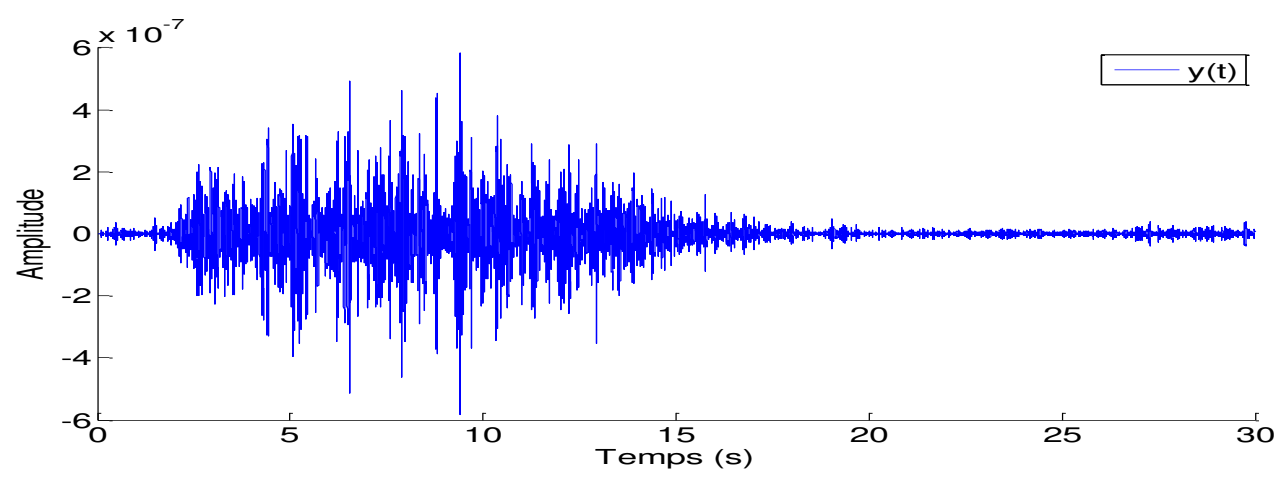

Figure 4.Earthquake accelerogramMay 21, 2003 Boumerdes, Algeria[16].

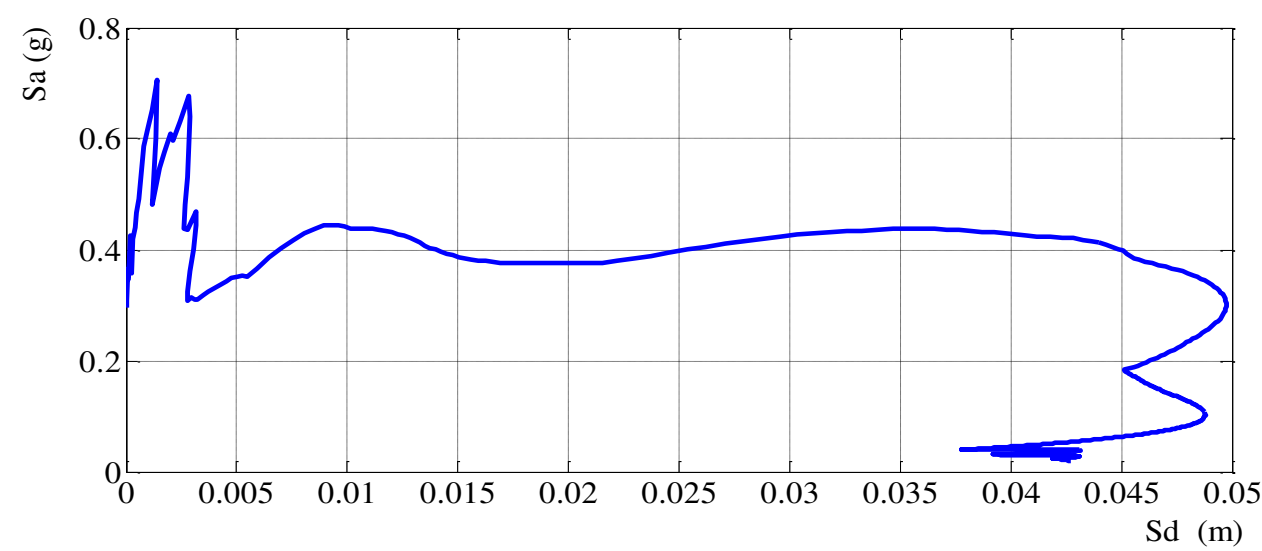

Figure 5. Spectrum of demand of the earthquake of Boumerdes May $212003(\xi=5 \%)[16]$. 
Based on Ansys analysis, bridge piers structure as shown in Figure 6 present tetrahedral mesh characteristics with a number of DOF of 45,927, a number of tetrahedral elements of 45,352 and a corresponding number of nodes of 15,309 . The use of computed pricipal stresses allows for the calculation of dynamic stresses and the verification of the RC strength bound.It is worth noting that this dynamic analysis necessitates the computation of numerous time steps and handles large matrices reaching 45,927dof. On the other side, in sum 12 Ansys corresponding batch files for each simulation case have been carried out. Obtained results are shown in Figures 6 to 9 and represent a graphical progression of the dynamic solution.This study using the meshing process as well as thesolving is carried out by the Ansys finite element software, with an analyzing programming batch for a generated mesh data file.It is also worth noting that the time required to mesh the structure is not included in the analysis time range's CPU time.We previously created and saved these meshes in order to use them in Ansys commands batch files that summarize the participation rate of the modal masses, taking into account the first three modes of participation rates of the most important masses.

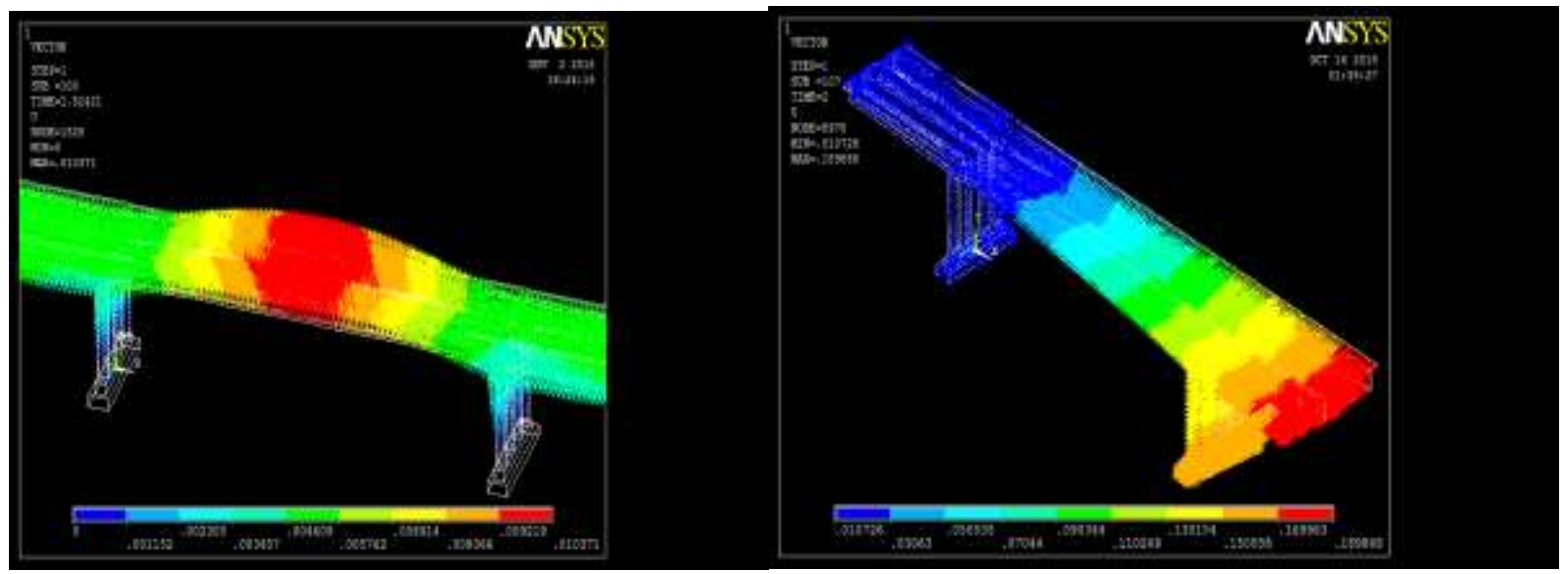

Figure 6 Representation of displacement Vector mode1.

Figure 7Representation of displacement Vector mode 2 .

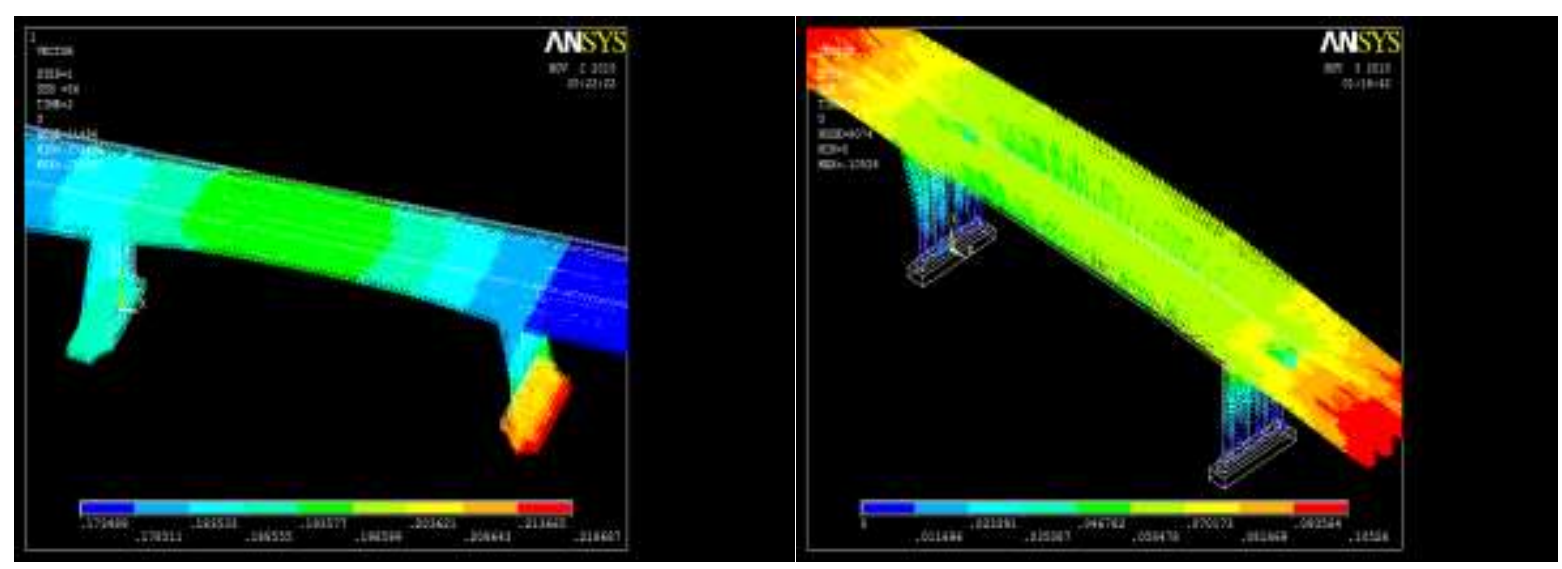


Figure 8Representation of displacement Vector mode3Figure 9 Representation of displacement Vector mode4.

\subsection{Capacity curve}

The horizontal force at the building's base as a function of displacement is represented by the capacity curve.In general, it is composed of a linear elastic phase followed by a non-linear phase corresponding to the formation of flexural and shear hinges, until the moment of rupture (Bhandari, Mohitet all).

Figure 9 represents the curves of capacity and development of plastic hinges obtained by a Pushover analysis with and without P- $\Delta$ effect, respectively (P- $\Delta$ : the effect of secondary momentum due to normal effort $\operatorname{PxMsec}=\operatorname{Px} \Delta$ ).

Results of the nonlinear analysis of the sections (M- $\varphi$ ) obtained by Response 2000 are shown below for two different sections (crosshead, column) of BB2.

\subsection{Obtained results}

Figures 10 represent the curves of capacity and development of plastic hinges obtained by a Pushover analysis with and without P- $\Delta$ effect, respectively (P- $\Delta$ : the effect of secondary momentum due to normal effort $\operatorname{PxMsec}=\operatorname{Px} \Delta$ ).

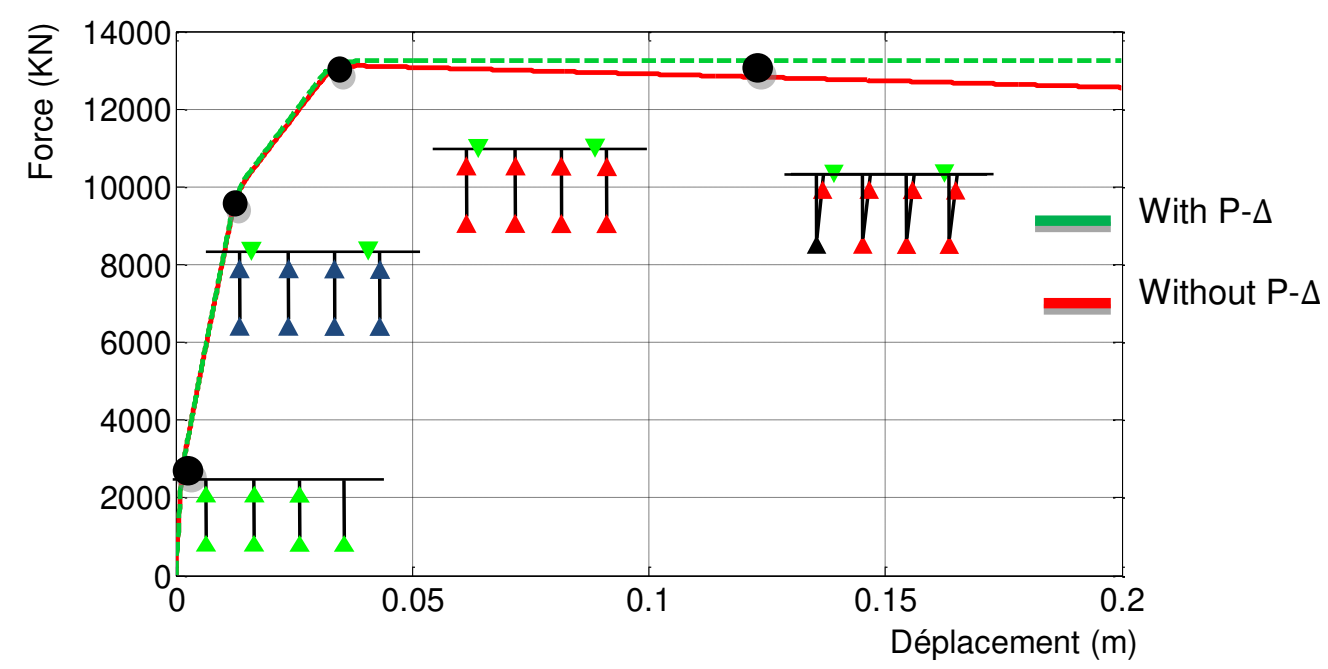

Figure 10. Curve of capacity and condition of plastic hinges with and without P- $\Delta$. 
Figure 10 illustrates the difference between the two capacity curves (with and without P- $\Delta$ ), as we see the compatibility of the two curves up to a threshold (the point indicated in the figure) and after a separation which explains the influence of P- $\Delta$ on the behavior. In Table 3 below, the ductility of the two curves are given.

The 'Pushover' curves (as presented in Figure 10) illustrate the behavior that is closer to the real behavior of our structure. These curves are characterized initially by an elastic part containing the cracking of the concrete up to the elastic limit designated by the first point of plasticization of the steels then they increase while describing the behavior of the structure in its inelastic phase, finally, a significant degradation of the lateral stiffness BB2 is observed until the rupture is reached by a formation of a ruined mechanism. The maximum displacement associated with the rupture is equal to $3.82 \mathrm{~cm}$ corresponding to the ultimate lateral displacement of BB2.

Table 3.Obtained results (with and without $\mathrm{P}-\Delta$ ).

\begin{tabular}{|c|c|c|c|c|c|}
\hline & Dy $(\mathrm{mm})$ & $\mathrm{Fy}(\mathrm{kN})$ & $\mathrm{Du}(\mathrm{mm})$ & $\mathrm{Fu}(\mathrm{kN})$ & $\mu$ \\
\hline with P- $\Delta$ & 11.91 & 9323.075 & 35.44 & 13072.68 & 2.98 \\
\hline without P- $\Delta$ & 11.91 & 9359.857 & 35.2 & 13187.88 & 2.95 \\
\hline
\end{tabular}

where; Dy is the displacement at the summit for the first plastification of steels, Du is the ultimate displacement at the summit, Fy is the strength at the base for the first plastification of steels, Fy is the ultimate strength at the base and $\mu$ corresponds to the ductility.
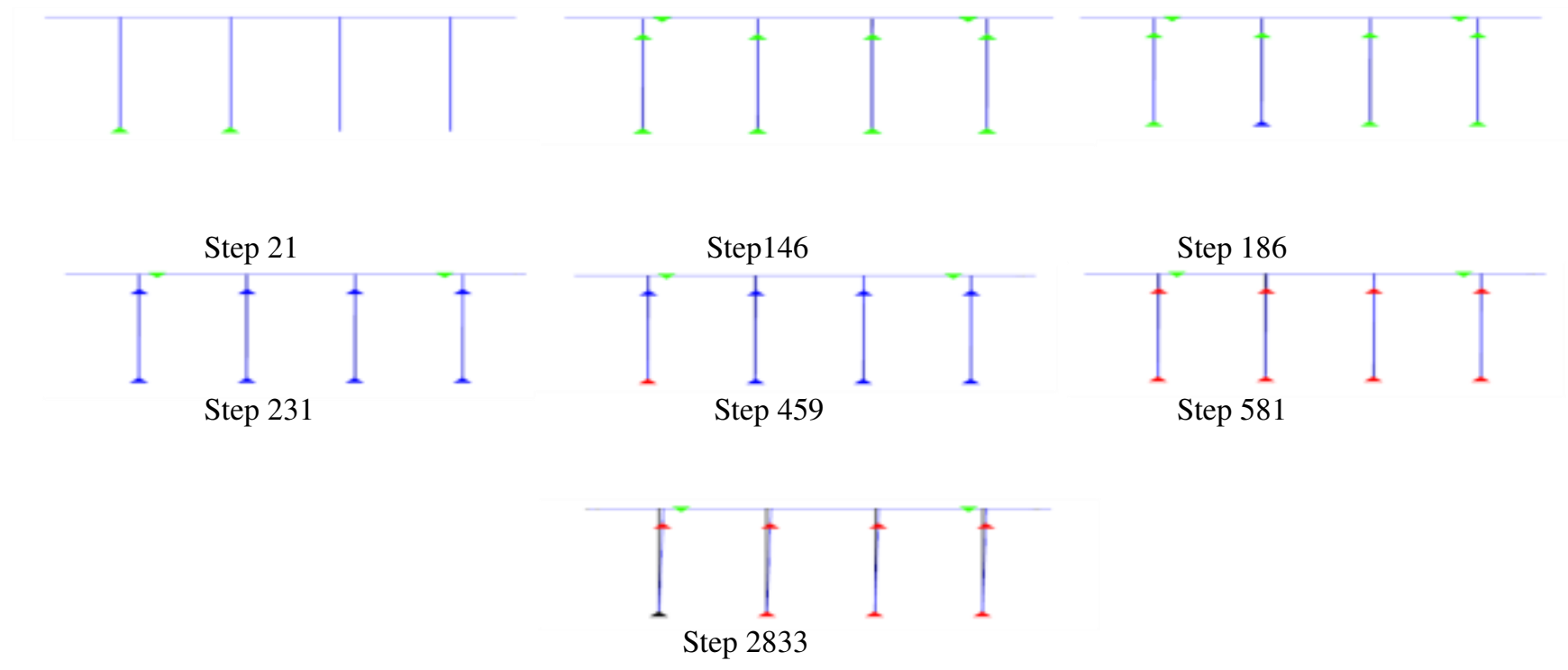

Figure 11 Development of plastic hinges of the most important events allowed 3,000 steps. 


\section{Performance point during the Boumerdes earthquake}

\subsection{Determination Performance point by PBSD method}

The basic principle of seismic computation is essentially to provide an acceptable degree of security thus reducing the risks related to failures, to disasters and the loss of life. In seismic codes and regulations, the study of the response of structures under seismic action is conducted using simplified methods according to the nature of the structure and its destination. Technical analysis of these structures consists essentially in comparing a "demand" parameter to a "capacity" parameter. The shear force at the base of a structure is a parameter traditionally used for the seismic design of structures. The engineer calculates the stress caused by an earthquake at the base of the structure, and compares it to the resistance of the latter. Otherwise, new techniques for checking and dimensioning reinforced concrete structures consist in choosing the performance objectives and thus developing an appropriate preliminary design. The evaluation of seismic demand and the capacity of the structure make it possible to verify if the design satisfies the purpose? In that case, it is judiciable to use the PBSD method .

ATC40 (Applied Technology Council, 1996) is mainly based on the characterization of the capacity of the structure and the determination of the seismic demand in one hand, and on a process of verification of the performance fixed in advance by the owner jointly with the engineer at the beginning of the project on the other hand. This ATC40 strategy is commonly known as the «Capacity Spectrum Method (CSM)». The main interest of the CSM method is to superimpose a curve which represents the resistance capacity of a structure resulting from a nonlinear static analysis (Pushover) with a representative curve of the demand due to the earthquake (response spectrum). The intersection leads to the point of performance .

Figure 12 depicts the bilinear capacity spectrum representation as well as the superposition of demand and capacity spectrums (Step 1 in the procedure A of ATC40). The steps of ATC technique A should be followed in order to estimate the earthquake strain and locate the point of performance, and the results are shown in Figure 12 below. 


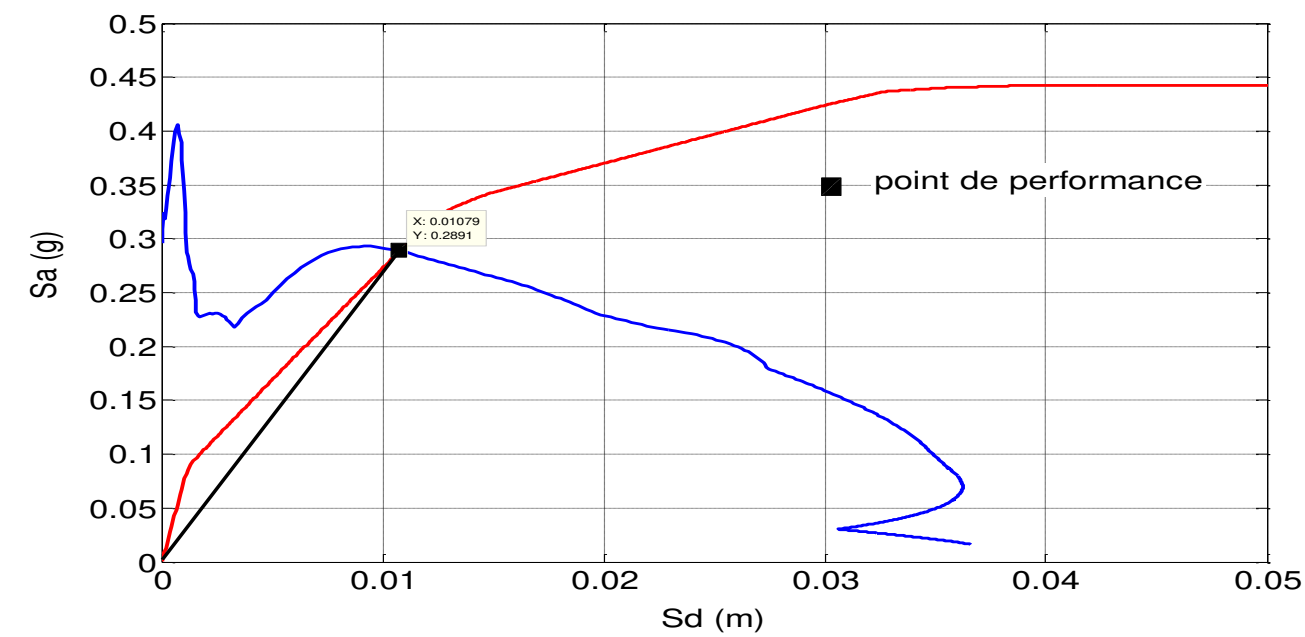

Figure 12. Evaluation of the BB2 performance point for the Boumerdes earthquake $(\xi=21.9 \%)$.

The CSM method gives good performance point for the Boumerdesearthquakes:

$\mathrm{Sd}=0.0108 \mathrm{~m}$.

$\mathrm{Sa}=0.289 \mathrm{~g}$.

This point estimates the maximum displacement as well as the shear at the base and describes the state of damage.

$$
\begin{array}{ll}
\mathrm{Sd}=\frac{\delta}{\mathrm{PF}_{1} \emptyset_{1, \mathrm{~S}}} \delta=\mathrm{Sd} \times \mathrm{PF}_{1} \times \emptyset_{1, \mathrm{~S}} \text { So } ; \text { we get } ; & \delta=0.0108 \mathrm{~m} \\
\mathrm{Sa}=\frac{\mathrm{V}}{\alpha_{1} \mathrm{~W} / \mathrm{g}} \mathrm{V}=\mathrm{Sa} \times \alpha_{1} \times W / g & \mathrm{~V}=8657.69 \mathrm{kN}
\end{array}
$$

From Figure 12, one can notice that $\mathrm{BB} 2$ remains in the elastic domain (before the plastification of steels), but the state of damage of the concr Designers may be able to use this relationship to compare defined qualitative boundaries in PBSD codes.ete is a little advanced as we see the appearance cracks at the top and bottom of the columns and the crosshead as shown in Figure 12.This figure explains the damage state of BB2. 


\subsection{Determination Performance point by superposition Stiffness-Based Damage Index and damage drift}

The analytical results show that obtained drift values at the operational level are conforms to the values specified in the code; however, they are inconsistent with those at the other performance levels. This mismatch could be caused by members with limited plastic rotation. This difficulty can be overcome by calculating the real drift using the crack section's lower gross inertia.

A pushover cannot be used to define a collapse zone; however, the drift criteria can be utilized to determine the zone.If a zone can be inserted, the drift criteria can then be plotted as the structural collapse zone.Designers may be able to use this relationship to compare defined qualitative boundaries in PBSD codes.The relationship between level of performance and damage value, as measured by the introduced zone of structural destruction, is investigated in this study.

Table 4.Collapse mechanism for Bridge.

\begin{tabular}{|c|c|c|c|c|c|c|c|c|c|c|}
\hline \multirow[b]{2}{*}{ Steps } & \multirow[b]{2}{*}{$\begin{array}{l}\text { disp } \\
(\mathbf{m m})\end{array}$} & \multirow{2}{*}{$\begin{array}{c}\text { Strength } \\
(\mathbf{k N})\end{array}$} & \multicolumn{7}{|c|}{ Different performance levels } & \multirow[b]{2}{*}{ Remarks } \\
\hline & & & A-B & $\mathrm{B}-\mathrm{IO}$ & IO-LS & $\begin{array}{l}\text { LS- } \\
\text { CP }\end{array}$ & $\begin{array}{c}\mathrm{CP}- \\
\mathrm{C}\end{array}$ & C-D & D-E & \\
\hline 1 & 0,024 & 59,6 & 16 & 0 & 0 & 0 & 0 & 0 & 0 & $A-B$ \\
\hline 16 & 1,03 & 2320,124 & 14 & 2 & 0 & 0 & 0 & 0 & 0 & first hinge in $\mathrm{B}-\mathrm{IO}$ range \\
\hline 180 & 12,02 & 9324,108 & 6 & 9 & 1 & 0 & 0 & 0 & 0 & first hinge in IO-LS range \\
\hline 452 & 30,04 & 12609,2 & 6 & 2 & 7 & 1 & 0 & 0 & 0 & first hinge in LS- CP range \\
\hline 650 & 38,24 & 13112,64 & 6 & 2 & $\mathbf{0}$ & 7 & $\mathbf{0}$ & 1 & 0 & first hinge in collapse range \\
\hline 2836 & 186,75 & 12601,8 & 4 & 2 & $\mathbf{0}$ & 2 & $\mathbf{0}$ & 1 & 7 & collapse \\
\hline
\end{tabular}

FEMA 356 (2000) and ATC 40 have always offered simple and uncomplicated drift criteria for identifying the global damage condition of the RC structure by using pushover analysis.Table 5 shows the performance of a structure based on the various drift restrictions.The criterion for drifting is determined according to the following relation;

$$
D I_{\text {drift }}=\frac{\Delta_{m}}{H}
$$

where $\mathrm{H}$ is the bridge's height and $\Delta_{m}$ denotes the maximum displacement at a focalpoint. 
The analytical results revealed that the obtained drift values at the operational level were conform to the values stated in the code; however, they were inconsistent with those at the other performance levels. This discrepancy could be caused bycomponents with limited plastic rotations. This difficulty can be overcome by measuring the real drift using the crack section's lower gross inertia.

Table 5.Drift limits at various performance levels (FEMA 356, 2000; ATC 40,1996).

\begin{tabular}{|l|l|l|}
\hline Performance level & Remarks & Drift \% \\
\hline (OP) Operational level & Construction does not undergo any damage & $<0.7 \%$ \\
\hline (IO)Immediate occupancy level & Constructionelements are partially damaged & $1 \%$ \\
\hline (LS)Life safety level & $\begin{array}{l}\text { Construction and non-structural elements are remarkably } \\
\text { damaged }\end{array}$ & $2 \%$ \\
\hline (CP)Collapse Prevention level & Construction is about to collapse & $4 \%$ \\
\hline
\end{tabular}

Stiffness-based damage index DIc relies on structural stiffness degradation during the pushing process (pushover). The stiffness can be used to compare the intact stiffness with the stiffness value of the expected performance level. The intact stiffness corresponds to the elastic range of the operational level. In assessing the stiffness at an intended level of performance, incremental displacement address the accumulated effect that has not been considered in previous studies for the formulation of damage, It is assumed that the appearance of a plastic hinge or the first fracture inside the operating level is an indicator of intact stiffness.

Figure 13 represents the percentage of stiffness-based damage index in the bridge with respect to the percentage drift of the analysis of an $\mathrm{RC}$ frame. It is obvious from these variance that at the formation of the first plastic hinge, DI is equal to zero at the operational level, DI is equal to $44 \%$ at the immediate occupancy, at the life protection range DI is equivalent to $62 \%$, DI is equal to $69 \%$ at the collapse prevention level, and $70 \%$ at the collapse level. 


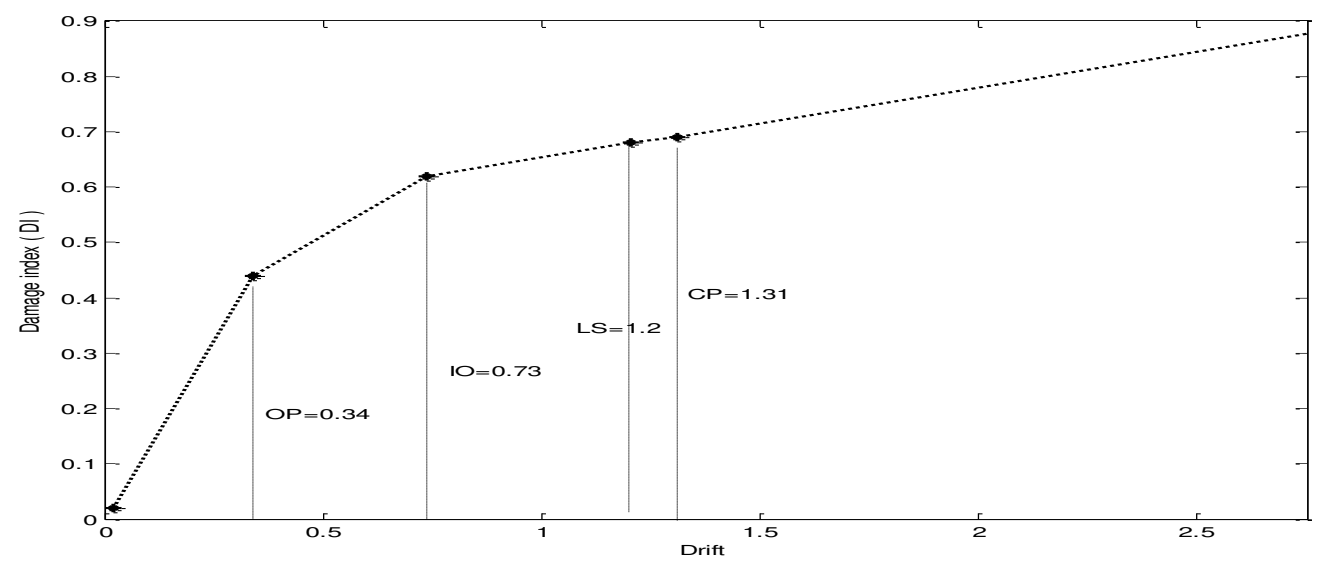

Figure 13.Variation in stiffness-based damage indices of Bridgewith drift (\%).

Table6 illustrates the evaluation of bridge I subjected to various lateral loads. For each displacement increase, the capacity curve reflects the deterioration of structural stiffness. It means that the deterioration of stiffness often takes the same path. The value of the damage is associated with different levels of performance following plastic hinge formation sequences and their transfer from one level of performance to another. Extended structural damage has a direct correlation to the variation in structural stiffness and it is useful to study this variation.

Figure 13 illustrates the change in bridge stiffness and demonstrates clearly that the structural stiffness continue to decrease with each increase in displacement in the elastic state, Presenting the consecutive yield of structural load carrying elements.

Table 6Stiffness-based damage indices for the Bridge.

\begin{tabular}{|c|c|c|c|c|c|c|c|c|}
\hline Step & $\begin{array}{l}\text { disp } \\
(\mathrm{mm})\end{array}$ & $\begin{array}{c}\text { Strength } \\
(\mathrm{kN})\end{array}$ & $\begin{array}{l}\text { Stiffness } \\
(\mathrm{kN} / \mathrm{m})\end{array}$ & $d_{c} K_{0}$ & $\begin{array}{l}\left(d_{i+1}\right. \\
\left.-d_{i}\right) K_{i}\end{array}$ & $\begin{array}{l}\sum_{i=0}^{n-1}\left(d_{i+1}\right. \\
\left.-d_{i}\right) K_{i}\end{array}$ & $D I_{c}$ & Remark \\
\hline 1 & 0.02 & 259.8 & 12990.0 & $/ /$ & $/ /$ & $/ /$ & $/ /$ & $/ /$ \\
\hline 16 & 0,091 & 430,50 & 4730,77 & 430,50 & 430,50 & 430,50 & 0,00 & $A-B$ \\
\hline 19 & 1,03 & 2320,12 & 2252,55 & 4872,69 & 2320,12 & 2750,62 & 0,44 & the first hinge in $\mathrm{B}-\mathrm{IO}$ range \\
\hline 180 & 12,02 & 9324,11 & 775,72 & 56863,86 & 18648,22 & 21398,84 & 0,62 & the first hinge in IO-LS range \\
\hline 452 & 60,04 & 12609,20 & 210,01 & 284035,43 & 63046,01 & 84444,85 & 0,69 & the first hinge in LS- CP range \\
\hline 2836 & 100,28 & 13113,00 & 130,76 & 474401,62 & 65565,01 & 150009,85 & 0,70 & collapse range \\
\hline
\end{tabular}




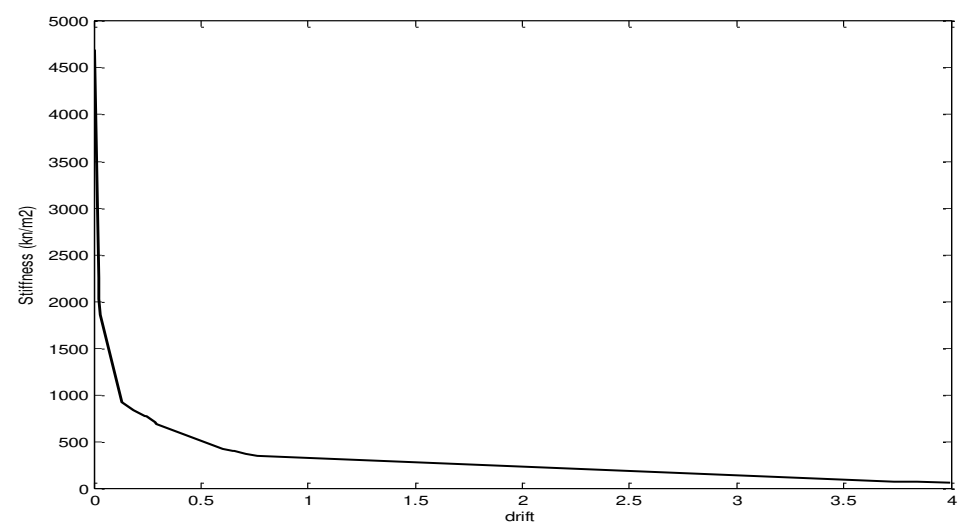

Figure 14 Variation of Structural Stiffness at Different PerformanceLevels for of bridgewith drift (\%).

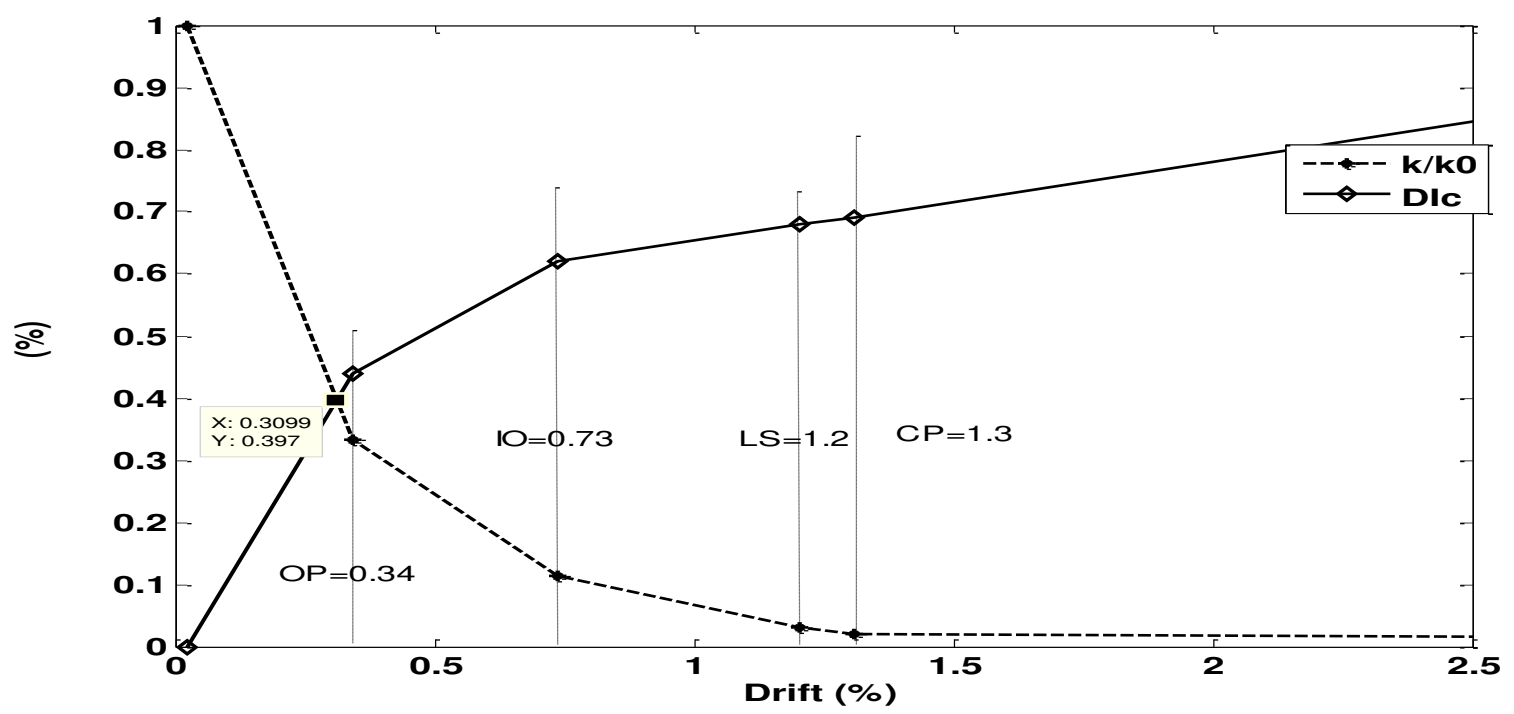

Figure 15 Superposition of the variation in stiffness-based damage indices of the bridge with drift damage andthe variation of structural stiffness at different performance levels of the bridge with drift damage (\%).

Figure 15 shows the superposition of the variation in stiffness-based damage indices of the bridge with drift damage and the variation of structural stiffness at different performance levels for of the bridge with drift damage (\%). To estimate the earthquake strain and find the point of performance by a new approach, one has to follow the procedure presented in Figure 15.

The method gives a good performance point for the Boumerdes earthquakes:

$D I_{\text {drift }}=\frac{\Delta_{m}}{H}=0.309 \%, \Delta_{m}=H * D I_{\text {drift }}=>\Delta_{m}=0.016 \mathrm{~m}$ with $H=5.395 \mathrm{~m}$,

$$
K_{0}=12990.00 \mathrm{KN} / \mathrm{m}
$$


$\frac{K}{K_{0}}=0.397 \%=>K=0.397 \%\left(K_{0}\right)=515703 K N / m$

$\mathrm{V}=0.397 \%\left(K_{0} * \Delta_{m}\right)=0.397 \%\left(K_{0} * H * D I_{\text {drift }}\right)=0.394(12990.00 * 1.6)=8251.248 \mathrm{KN} / \mathrm{m}$.

This point estimates the maximum displacement as well as the shear at the base and describes the state of damage.

$$
\begin{aligned}
& \mathrm{Sd}=\frac{\delta}{\mathrm{PF}_{1} \emptyset_{1, \mathrm{~s}}} \delta=\mathrm{Sd} \times \mathrm{PF}_{1} \times \emptyset_{1, \mathrm{~S}} \text { So } ; \text { we get } ; \quad \delta=0.0108 \mathrm{~m} \\
& \mathrm{Sa}=\frac{\mathrm{V}}{\alpha_{1} \mathrm{~W} / \mathrm{g}} \mathrm{V}=\mathrm{Sa} \times \alpha_{1} \times W / g \delta=8657.69 \mathrm{kN}
\end{aligned}
$$

Table 7 Point of performance by ATC40 vs Point of performance by our methods.

\begin{tabular}{|c|c|c|}
\hline & $\begin{array}{c}\text { Point of performance } \\
\text { by ATC40 }\end{array}$ & $\begin{array}{c}\text { Point of performance by our } \\
\text { methods }\end{array}$ \\
\hline$\delta(\mathrm{m})$ & 0.0108 & 0.016 \\
\hline$V(K N)$ & 8657.69 & 8251.248 \\
\hline
\end{tabular}

From Table 7, one can notice that the maximum displacement of point of performance by both methods is almost of the same order as well as for the shear value.

\section{Conclusion}

In this research work, damage assessment was carried out following three stages: (a) a static nonlinear pushover analysis of the frame; (b) a determination of the structure response under anearthquake ground motion; (c) a dynamic study.The proposed approach, described by equations (2) and (3), is employed to assess the damage index for the entire structure and for each storey. Besides, an analysis of the performance point of a bridge has been developed using a stiffness-based damage index and a drift damage to assess the damage to reinforced concrete moment resisting frames.

Additional analysis taking into account dynamic inelastic time-history was also performed on a bridge subjected to earthquake records.Besides, the damage developed during loadings wasassessed by the stiffness-based damage index. On the other hand, damage - drift 
relationship were derived by applying a superposition taking in consideration their effects. It is also proven that the proposed performance point and damage indices are capable to estimate the damage index of bridge frames. The validity of the proposed approach was checked by comparing the predicted values to the ones considered exact in the literature.

The suggested method outperforms the state-of-the-art methodology such that the acceptable value of the performance point can be determined without having to generate the so-called acceleration displacement response spectrum. This latest is required when using the capacity spectrum procedure. The correctness of the proposed approach is confirmed by comparing the results to those previously obtained using procedure ATC 40 and comparing them to those considered accurate in the research.The proposed methodology was validated by a relatively good agreement between the maximum displacements and shear forces obtained by the numerical method and those obtained during testing.

The prediction of structural behavior has become a part of a new design process such as performance and displacement based approaches. The seismic demands in displacement and force seismic for a design can be determined by taking into account the interaction with the structural capability. However, computing the resultant performance point according to this approach requires a significant amount of time and efforts. For this reason, the determination of the performance point of structures should be obtained in a simpler way by the nonlinear static analysis procedure. Throughout this research work, a simple but correct alternative strategy is proposed on behalf of practicing design engineers accumulation of damage owing to earthquake force continues to soften, resulting in a period shift to the longer side.

\section{References}

Mohd.Zameeruddin, Keshav K. Sangle.Damage Assessment of Reinforced Concrete Moment Resisting Frames using Performance-based seismic evaluation Procedure, Journal of King Saud University-Engineering Sciences https://doi.org/10.1016/j.jksues.2020.04.010

Mihai Mihaită (2015). A theoretical review of the damage indices used to model the dynamic behavior of reinforced concrete structures. Bulletin of the polytechnic institute of Lasi, construction and architectural section 63(2): 109-119. 
ATC-40.Seismic evaluation and retrofit of concrete building, Applied Technical Council, Redwood City, USA, 1996.

FEMA-273.NHERP Guidelines for Seismic Rehabilitation of Buildings, Federal Emergency Management Agency, Washington DC, USA, 1997.

FEMA 356.Pre-Standard and Commentary of Seismic Rehabilitation of Building, Federal Emergency Management Agency, Washington DC, USA, 2000.

FEMA 440. Improvement in Nonlinear Static Seismic Analysis Procedures, Washington (DC): Federal Emergency Management Agency, 2005.

Ghobarah A. Seismic assessment of existing RC structures, Progress in Structural Engineering Material, No. 1, 2 pp. 60-71, 2000.

FEMA 445.Next-Generation Performance-Based Seismic Design Guideline Program for New and Existing Buildings, Washington (DC), Federal Emergency Management Agency, 2006.

Ranjkesh, S.H., Asadi, P., Hamadani, A.Z., Seismic collapse assessment of deteriorating RC bridges under multiple hazards during their life-cycle. Bull Earthquake Eng 17,50455072,2019. https://doi.org/10.1007/s10518-019-00647-8.

Mahboubi, S., Shiravand, M.R., Seismic evaluation of bridge bearings based on damage index. Bull Earthquake Eng 17, pp. 4269-4297, 2019. https://doi.org/10.1007/s10518-01900614-3

Hosseini, S.H., Naderpour, H., Vahdani, R., Evaluation of pounding effects between reinforced concrete frames subjected to far-field earthquakes in terms of damage index. Bull Earthquake Eng (2021). https://doi.org/10.1007/s10518-021-01259-x

Fajfar P., Dolšek M. (2014), Pushover-Based Analysis in Performance-Based Seismic Engineering - A View from Europe. In: Fischinger M. (eds) Performance-Based Seismic Engineering: Vision for an Earthquake Resilient Society. Geotechnical, Geological and Earthquake Engineering, vol. 32.Springer, Dordrecht.https://doi.org/10.1007/978-94-0178875-5_19 
Zhou, C., Chase, J.G., Rodgers, G.W., Damage assessment by stiffness identification for a full-scale three-story steel moment resisting frame building subjected to a sequence of earthquake excitations, Bulletin of Earthquake Eng. 15, 5393-5412, 2017.https://doi.org/10.1007/s10518-017-0190-y

Ghobarah A. Seismic assessment of existing RC structures, Progress in Structural Engineering Material, No. 1, 2 pp. 60-71, 2000.

Ghobarah A, Abo-Elfath H, Biddah A (1999), Response-based damage assessment of structures, Earthquake Engineering and Structural Dynamics 28: 79-104.

Ghobarah, A. (2001), Performance-based design in earthquake engineering: State of development, Engineering Structures, Vol. 23, pp. 878-884, Doi: 10.1016/S01410296(01)00036-0

Mohd.Zameeruddin, Keshav K. Sangle,Damage assessment of reinforced concrete moment resisting frames using performance-based seismic evaluation procedure,Journal of King Saud University - Engineering Sciences,Vol. 33, Issue 4,2021,

Williams, M.S., Sexsmith, R.G. (1995), Seismic damage indices for concrete structures: A State-of-the-Art Review, Earthquake Spectra, 11:2, 740-757.

N. M. Newmark, E. Rosenblueth, Fundamentals of Earthquake Engineering, Prentice-Hall, Englewood Cliffs, NJ, 1971.

Mohammad S. Alhaddad, Khalid M. Wazira, Yousef A. Al-Salloum, Husain Abbas,Ductility damage indices based on seismic performance of RC frames,Soil Dynamics and Earthquake Engineering,Vol. 77, pp. 226-237,ISSN 0267-7261, 2015.

https://doi.org/10.1016/j.soildyn.2015.05.014.

S. Toussi and J. T. P. Yao, Hysteresis identification of existing structures, Journal of Engg. Mech., ASCE 109(5), pp. 1189-1203, 1982.

M. S. L. Roufaiel, C. Meyer, Analysis of damaged concrete frame buildings, Technical Report No. NSF-CEE-81- 21359-1, Columbia University, New York, NY, 1981. 
J. E. Stephens, J.T.P. Yao, Damage assessment using response measurements', J. Struct.Engng.ASCE 113(4), pp. 787-801, 1987.

Banon H., Veneziano D. (1982), Seismic safety of reinforced concrete members and structures, Earthquake Engineering and Structural Dynamics, 10(2), pp. 179-193. DOI:10.1002/eqe.4290100202.

Miner, M. A. (1945), Cumulative damage in fatigue, Journal of Applied Mechanics, 12(3), 159-164. DOI 10.1115/1.4009458

Wang, D., Feng, Q., Wang, G. X. (2004), A modified Park and Ang seismic damage model considering low-cycle fatigue life, China Civil Engineering Journal, 37(11), 41-49 (in Chinese).DOI 10.3321/j.issn:1000-131X.2004.11.007.

Y. J. Park, A. H.-S.Ang, Mechanistic seismic damage model for reinforced concrete, JournalStruct. Div. ASCE 111(4), 722-739, 1985.

Y. S. Chung, C. Meyer, M. Shinozuka, Seismic damage assessment of reinforced concrete members, Report NCEER-87-0022, National Center for Earthquake Engineering Research, State University of New York at Buffalo, Buffalo, NY, 1987.

E. DiPasquale, A. S. Cakmak, Identification of the serviceability limit state and detection of seismic structural damage', Report NCEER-88-0022, National Center for Earthquake Engineering Research, State University of New York at Buffalo, NY, 1988.

Julian Carrillo, Damage index based on stiffness degradation of low-rise RC walls, Earthquake Engg. Struct.Dyn.,44:831-848, 2015. https://doi.org/10.1002/eqe.2488

Leila Soufeiania, Sudharshan N. Ramanb, Mohd Zamin BinJumaata, Ubagaram Johnson Alengarama, Ghasem Ghadyania, Priyan Mendisc, Influences of the volume fraction and shape of steel fibers on fiber-reinforced concrete subjected to dynamic loading, A review, Engineering Structures, Vol. 124, pp. 405-417, 2016. 
Doo-YeolYoo, Soonho Kim, Gi-Joon Park, Jung-Jun Park, Sung-Wook Kim ,Effects of fiber shape, aspect ratio, and volume fraction on flexural behavior of ultra-high-performance fiberreinforced cement composites, Composite Structures, Vol. 174, pp. 375-388, 2017.

Bathias, C. (2009), Matériaux Composites, ed. Dunod C.G.S. (2003), RPA: Règlesparasismiquesalgériennes, RPA99/version 2003.

Bhandari, Mohit, Bharti, ShivDayal, Shrimali, Mahendra Kumar, Datta, TusharKanti, Applicability of Capacity Spectrum Method for Base-Isolated Building Frames at Different Performance Points, Journal of Earthquake Engineering, 2018 